\title{
Advances in neoplastic disease of the liver and biliary tract
}

\author{
P J Johnson, M L Wilkinson, J Karani
}

The last 25 years have seen an explosion of interest in hepatic and biliary neoplasia reflecting not only the worldwide importance of these tumours, but also the fact that recent advances in serological and radiological diagnosis and the new techniques of molecular biology have all had a major impact. It seems hard to believe that in 1965 , none of the hepatitis viruses had been identified and although 'Australian antigen' had just been described its significance was yet to be realised. Computerised tomography, ultrasonography and ERCP were all unheard of. The idea of useful tumour markers was still the stuff of oncologists' dreams, alphafetoprotein having only been recognised in animal studies in the year the first liver transplant programme was started (1964). This review aims to summarise progress over the period in question and highlight some of the contributions and current areas of interest of the Institute over this period.

\section{Historical overview}

In 1965 there were occasional perceptive suggestions that hepatocellular carcinoma might be aetiologically related to chronic infection with one of the hepatitis viruses. With the discovery of the association between 'Australia antigen' and hepatitis in 1967, however, the door was opened for a flood of papers soon to show an undoubted association of this tumour with hepatitis B virus infection. ${ }^{1}$ The crowning epidemiological study was that of Beasley et al who, in an ongoing follow up study of over 22000 male Chinese, clearly showed that those who were $\mathrm{HBsAg}$ seropositive were at a relative risk of over 100 for the development of hepatocellular carcinoma. ${ }^{2}$ At about the same time there were several reports that integrated HBV-DNA could be detected in the genome of hepatoma cell lines and in some samples of human liver tumour tissue. ${ }^{3}$ Another seminal observation was that certain animals, particularly woodchucks ${ }^{4}$ and Pekin ducks carried viruses (subsequently classified as 'hepadna' viruses) which are similar in genome size, morphology, and genome organisation to human hepatitis B virus. The woodchuck frequently develops chronic hepatitis and hepatocellular carcinoma which contains integrated WHV-DNA sequences and is, therefore, an excellent model for the investigation of hepatitis $B$ virus related carcinogenesis.

It is probably fair to say that molecular biological investigations made rather less progress than expected over the next decade, in explaining the mechanism of hepatitis B virus carcinogenesis. Some workers made the startling observation that even among alcoholic cirrhotic patients developing hepatocellular carcinoma and subjects with no serum markers of hepatitis
B virus infection, integrated HBV-DNA could be detected in tumour tissue. ${ }^{5}$ These observations remain controversial, and others have been unable to confirm them. ${ }^{67}$ There is currently no evidence that the viral DNA contains a transforming gene - that is, an 'oncogene' - and analysis of integrated viral segments has failed to reveal any consistent site of integration or common deletions or duplications.

The excitement over hepatitis B virus involvement overshadowed other possible aetiological factors particularly cirrhosis, the frequency of which amongst men with hepatocellular carcinoma had been commented upon for at least 50 years. ${ }^{8}$ In a large prospective follow up of 613 patients with different types of cirrhosis initiated in 1978 by Walter Melia and continued by Shams Zaman and Elizabeth Metivier, multivariate analysis showed that the major independent risk factors for the development of hepatocellular carcinoma were increasing age, 'non-UK' nationality and male sex. ${ }^{9}$ Interestingly, serum hepatitis B virus markers were not a significant risk factor implying that, in previous analyses, the risk associated with hepatitis B virus might have been confounded by the coassociation of hepatitis B virus infection with male sex and birth in areas of high incidence. The importance of cirrhosis as a major aetiological factor is now more widely accepted, at least in low hepatocellular carcinoma incidence areas, but the interactions with other aetiological factors including hepatitis B virus infection remain controversial.

\section{SEX HORMONES AND LIVER CANCER}

It had been long established that, in certain mouse strains, administration of testosterone significantly increases the frequency with which chemically induced hyperplastic nodules progress to hepatoma and castration of male animals decreases the frequency of this occurrence. ${ }^{10} \mathrm{In}$ 1966 in a preclinical study of steroids to be used in oral contraceptive preparations it was recorded that, '. . . Dr Bosner reported to the Committee (on the Safety of Drugs) that dosage with mestranol was associated with the production of nodules in rats which histologically showed various stages of nodular hyperplasia and the production of hepatoma . . . . It should therefore perhaps, not have come as a surprise when Baum ${ }^{12}$ and her colleagues described the development of hepatic adenomas in women taking oral contraceptive steroids, an association soon to become well accepted. The possible role of these agents in malignant liver disease was more controversial but an influential paper by James Neuberger in collaboration with Professor Richard Doll at Oxford suggested a small, but significantly increased, risk of hepatocellular 


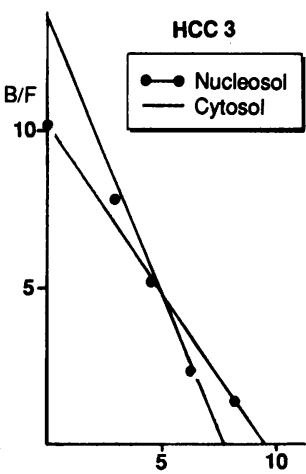

R 1881 bound $\times 10^{-10}(\mathrm{~mol} / \mathrm{l})$

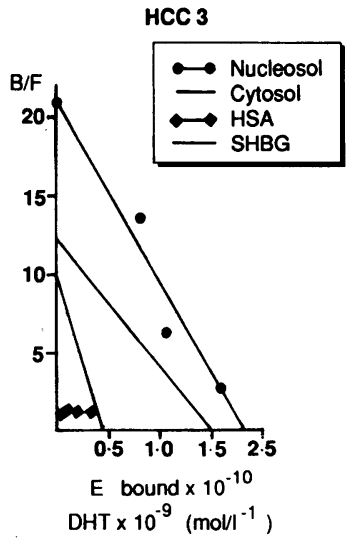

Figure 1: Scatchard plots of sex steroid binding in the cytosol and nucleosol of hepatocellular carcinoma. Androgen receptors and nucleosol of hepatocellular carcinoma. Androgen receptors receptors using oestradiol (from ref 14). (Reproduced by courtesy of $\mathrm{Br} \mathrm{J}$ Cancer.)

carcinoma after prolonged usage. ${ }^{13}$ Such observations, together with the previously noted predominance of men among cirrhotic subjects developing hepatocellular carcinoma, focused on the attention of many on the Unit to the role of sex hormones in hepatic neoplasia.

Jawed Iqbal and colleagues were the first to show the presence of androgen receptors ${ }^{14}$ in human liver tissue (Fig 1) which were identical to androgen receptors found in prostatic tissue. ${ }^{15}$ These data have since been confirmed ${ }^{16}$ as has the observation that human hepatocellular carcinoma tissue exhibits much higher concentrations of androgen receptors and $5 \alpha$-reduced androgens than normal liver tissue. ${ }^{14}$ is During these studies a new circulating sex-steroid binding protein, 'fetal steroid binding protein' was discovered in human fetal liver and the serum of hepatocellular carcinoma patients. ${ }^{17}$ This protein was later purified and shown to be present in normal serum. While its role is uncertain, its levels in hepatocellular carcinoma patients appear to correspond with response to therapy.

\section{DIAGNOSIS AND MONITORING RESPONSE TO} THERAPY

For all the work into serological tumour markers, alphafetoprotein, first described in the serum of a human with hepatocellular carcinoma in $1964^{18}$ is perhaps still the only one which is widely used in clinical practice. In the presence of a mass lesion in a cirrhotic liver a markedly raised level is sufficient to establish the diagnosis of hepatocellular carcinoma and monitoring of changes in serum levels can be invaluable in assessing response to therapy (Fig 2). $1{ }^{120}$ Nonetheless, some of the initial enthusiasm for using alphafetoprotein to screen high risk populations for early detection of hepatocellular carcinoma has subsided with the recognition that there is some overlap between levels of alphafetoprotein in hepatocellular carcinoma and uncomplicated chronic liver disease, particularly while the tumour is small.

The fibrolamellar variant of hepatocellular carcinoma was described in detail in 1980 by Craig $e t a l^{21}$ and for the first time a primary malignant liver cell tumour with distinctive histological features (deeply eosinophilic cyto-

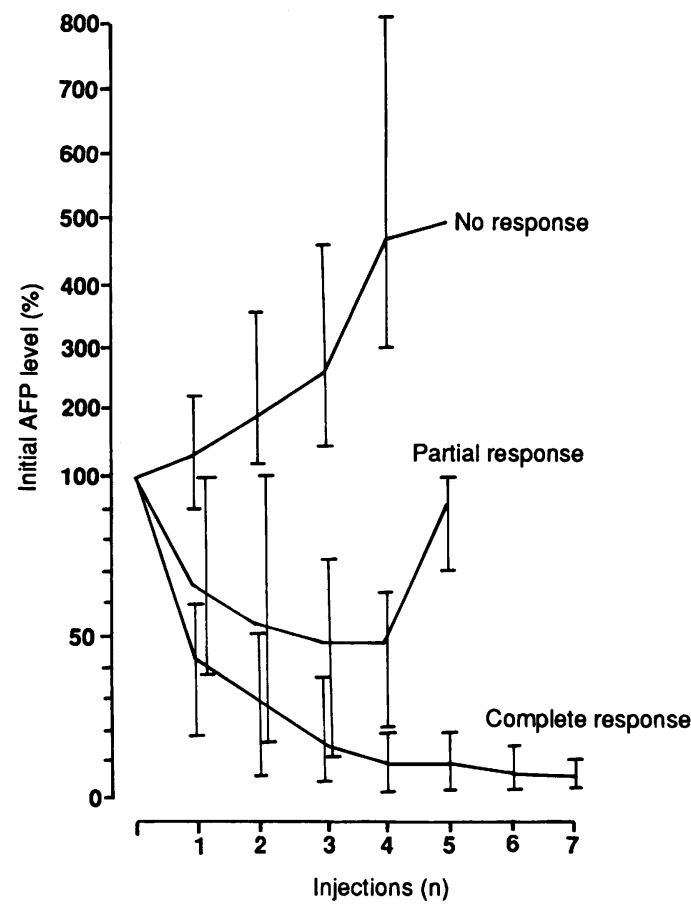

Figure 2: Response of alphafetoprotein during adriamycin therapy in relation to clinical response. Note that evidence of subsequent response can be seen after the first injection (from ref 19). (Reproduced by courtesy of the Lancet.)

plasm and pyknotic nuclei interspersed with parallel bundles of collagen resulting in fibrous septa) had a specific clinical counterpart. It occurs during adolescence, in a non-cirrhotic liver and is invariably alphafetoprotein seronegative and unrelated to hepatitis $B$ virus infection. The prognosis is somewhat better than with other histological types although very few patients will survive more than five years from diagnosis. At the suggestion of Iain MurrayLyon, vitamin $B_{12}$ binding protein was measured and in a series of 107 patients with hepatocellular carcinoma was shown to be a specific marker for this particular tumour variant. ${ }^{22}$

RADIOLOGY

The advent of clinical ultrasonography has had a great impact. ${ }^{23}$ It is now the first line investigation for screening high risk patients and monitoring response of liver tumours to therapy. Much of the original impetus came from Japan reflecting the combination of technological expertise and the high frequency of hepatocellular carcinoma and from where the concept of 'minute' carcinomas (usually defined as less than $3 \mathrm{~cm}$ in diameter), eminently suitable for resection, derived. ${ }^{24}$

There is now an extensive literature from the Far East on the role of lipiodol image enhancement in computed tomography diagnosis. ${ }^{25}$ The aim of this technique is to opacify the liver on a cellular, rather than a vascular basis. Lipiodol, an oily based contrast medium, is injected into the hepatic artery at the time of arteriography and sequential computed tomography scanning is carried out (Fig 3). Lipiodol is cleared from normal hepatic tissues but is said to accumulate in malignant tumours because of the 'leaky' character of neovascular tissue, coupled with the lack of lymphatic clearance from tumour tissue. 


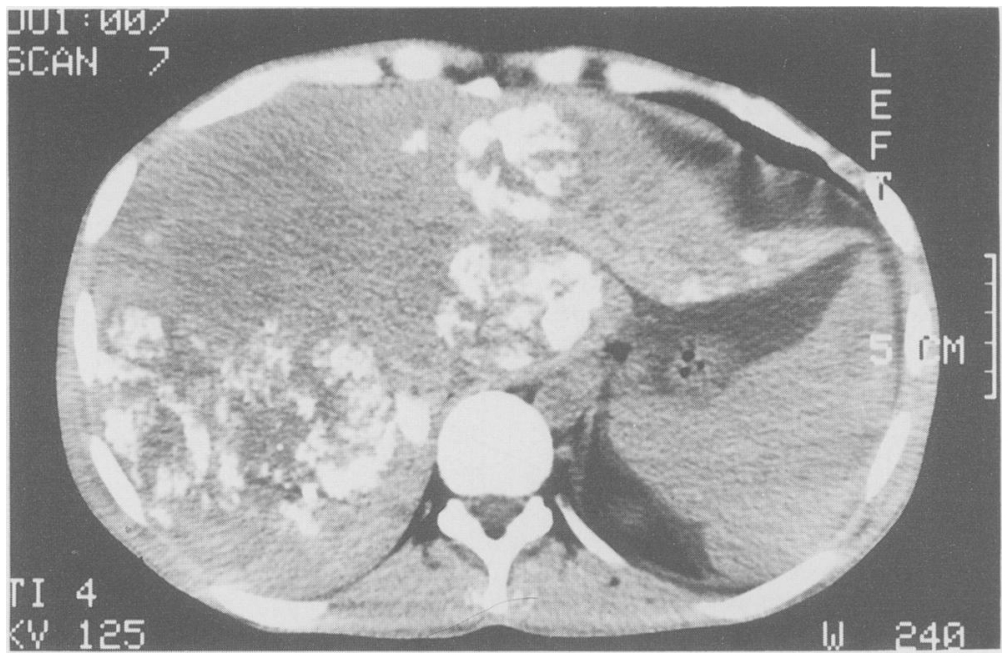

Figure 3: Lipiodol localised in an hepatocellular carcinoma after intraarterial injection.

Our current practice is that it should be reserved for smaller tumours, to confirm that a lesion is solitary, or in patients with raised alphafetoprotein, where conventional imaging has failed to show a tumour. It is of little value in patients with multicentric tumour, already confirmed on imaging. ${ }^{26} \mathrm{~A}$ recent study from King's has shown that combining described radiological criteria ${ }^{27}$ with clinical and biochemical parameters, accurately predicts the type of tumour, both benign and malignant, in over $90 \%$ of patients, when compared with subsequent histology obtained at resection of biopsy. ${ }^{28}$ As smaller tumours are detected histological proof of malignancy becomes increasingly important, and both computed tomography and ultrasound guided biopsy have now become routine procedures which have greatly increased the diagnostic accuracy and safety of percutaneous biopsy.

In a notable paper Ulrich Raeth, who arrived at the Institute in 1981 from Heidelberg with his own 'state of the art' ultrasound machine, described an accurate ultrasonic method for calculating liver volume. This was probably the only method which has been genuinely validated by ultrasonic measurement of liver volume in cadavers in the autopsy room and then by water displacement after removal! ${ }^{29}$

Hepatic arterial embolisation, a refinement of hepatic artery ligation, a technique investigated by Iain Murray-Lyon a decade earlier ${ }^{30}$ was widely used in the early 1980s and actively pursued in the radiology department by John Laws and Heather Nunnerly. Although used less now because there is little evidence of improved survival the technique has proved valuable in symptomatic control, particularly with regard to pain and the symptom of flushing and diarrhoea associated with carcinoid and other peptide producing tumours. ${ }^{31}$ Heather Nunnerly was largely responsible for the introduction of the iridium wire as a source of internal radiation for patients with inoperable cholangiocarcinoma, a technique which is now widely combined with stenting at endoscopic retrograde cholangio pancreatography. ${ }^{32}$

\section{TREATMENT AND PROGNOSIS}

There is no doubt that treatment has been the most disappointing area, one which has seen many false dawns. Other than those patients in whom the tumour is detected incidentally or presymptomatically as a result of screening, the outlook has probably changed little for any of the primary liver tumours. Indeed the use of coeliac plexus block for pain and biliary stenting to relieve obstructive jaundice, ${ }^{33}$ although not affecting survival, have probably done more for improvement of quality of life than any of the other attempts at treatment.

SURGERY AND LIVER TRANSPLANTATION

Surgery remains the only hope of 'cure' in patients with malignant liver tumours. Over the last 25 years there has been a gratifying reduction in the operative mortality and an increase in the number of patients considered 'operable', particularly in the Far East. This reflects a combination of better surgical and anaesthetic techniques, in particular appreciation of the segmental anatomy of the liver. About $40 \%$ of hepatocellular carcinoma patients without cirrhosis and in whom complete resection is obtained can now expect to live for five years, but this group represents only a small minority of the whole population of hepatocellular carcinoma patients. In the Far East surgeons are becoming increasingly enthusiastic about resection in the cirrhotic liver with a five year survival rate of up to $50 \%$ being quoted but Western experience with the cirrhotic liver has, to date, been less favourable. Bismuth reported that only 35 of 270 cirrhotic patients were operable and, of these, only 12 were alive at 16 months. ${ }^{34}$

Similarly, only a small percentage of tumours in the high bile duct or at the bifurcation are amenable to curative surgical resection. Amongst this group, the development of endoscopic stenting has been a major advance and is now the treatment of choice in most instances where it offers excellent palliation..$^{35}$ Low malignant bile duct lesions may also be amenable to endoscopic stenting and a consensus is being reached that this is the treatment of choice in the elderly, frail and ill. The stay in hospital may be shorter and the mortality less than for surgery ${ }^{36}$ which should probably be reserved for younger patients with a longer life expectancy.

Surgery is also being increasingly used in patients with metastatic colorectal metastases and guidelines as to which patients will benefit most are becoming available. For example, it appears that for a patient with one or two metastases from a Dukes grade B colonic carcinoma and a resection margin of greater than $1 \mathrm{~cm}$, the chances of five year survival reach almost $50 \% .^{37}$

Early experience with liver transplantation for hepatocellular carcinoma was disappointing; whilst the patients did uniformly well in the short term, tumour recurrence was the norm, ${ }^{38}$ presumably reflecting spread of clinically undetectable extrahepatic micrometastases to involve the new liver. Our more recent experience, however, has shown that such disappointing results are associated with large tumours and 
that patients with small ( $<4 \mathrm{~cm}$ in diameter) and/or asymptomatic tumours, do much better and seem to be one of the most suitable groups of patients for liver transplantation.

\section{CYTOTOXIC AND ANTI-HORMONAI CHEMOTHERAPY}

Early studies on cytotoxic chemotherapy saw the first collaborative ventures between the Royal Free, Charing Cross Hospital, and King's. The first suggested a modest response rate of around $25 \%$ with systemic arterial adriamycin ${ }^{19}$ in a series of 43 patients. Subsequent studies have not always been able to achieve even such modest levels reported but no other single drug or combination of drugs seem to have fared any better. Recent studies have shown that it is feasible to give full doses of adriamycin even in the presence of hyperbilirubinaemia but the response rate is still disappointingly low. ${ }^{36}$ Our current base line treatment for inoperable hepatocellular carcinoma, against which new therapies should be compared, is to administer three courses of adriamycin systemically at a dose of $60 \mathrm{mg} / \mathrm{m}^{2}$ (provided the serum bilirubin concentration is below $30 \mu \mathrm{mol} / \mathrm{l}$ ) at three weekly intervals. Where there is objective evidence of response in terms of a decrease in tumour or liver size, or a fall in the serum concentration of alphafetoprotein, the course should be completed (to a maximum dose of $550 \mathrm{mg} / \mathrm{m}^{2}$ ) otherwise treatment should be withdrawn.

After the detection of sex hormone receptors in hepatocellular carcinoma a prospective randomised controlled trial comparing tamoxifen plus doxorubicin with doxorubicin alone was undertaken. The first patient to enter the study responded dramatically and died, of an unrelated illness whilst in complete remission, three years after. Over the next two years, however, we saw no further such dramatic responses and indeed, in the final analysis, there was no difference in survival. ${ }^{39}$ A much more optimistic result using tamoxifen alone has recently been reported ${ }^{40}$ with a survival at one year of $40 \%$ in the tamoxifen treated group compared with zero in the untreated control group. If these results are confirmed they represent an exciting advance. We have also tried the alternative approach of using the antiandrogen cyproterone acetate in 25 cases. In all five patients with objective evidence of a response there was an associated fall in free 5 $\alpha$-dihydrotestosterone. ${ }^{41}$

SECONDARY TUMOURS AND THE INFUSAID PUMP Several early studies reported that intraarterial chemotherapy with FUDR led to high remission rates in patients with metastases from colorectal carcinoma but against this needed to be counted the side effects of repeated vascular access. With the development of permanently implantable systems such as the Infusaid pump these problems seem to have been overcome and recent controlled studies confirm that high remission rates are obtainable. Nonetheless it remains to be proved that these good remission rates are translatable into improved survival, particularly
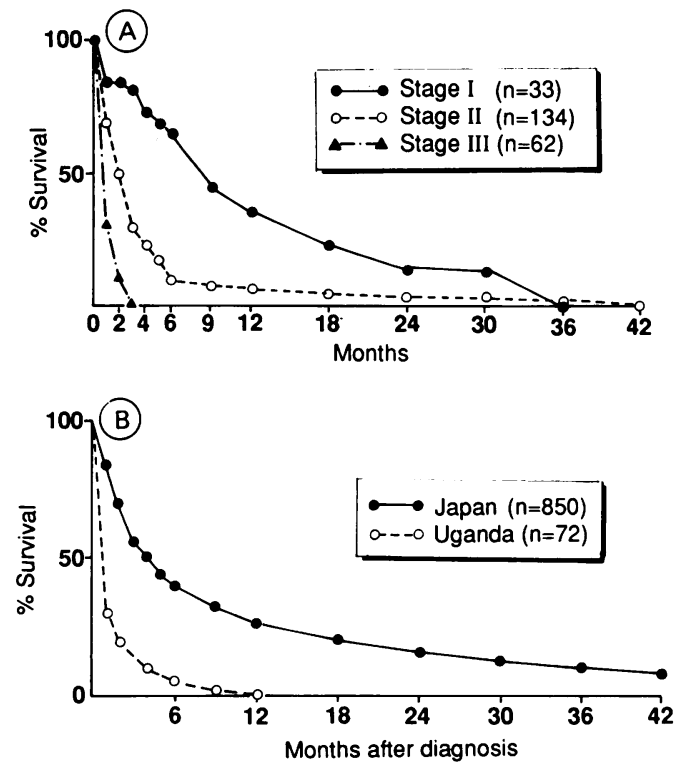

Figure 4: (a) Survival curves for 229 patients who received no specific treatment. The median survival was 0.7 months for stage III patients, and 2 months for 134 stage II patients, and 8.3 months for 33 stage I patients (from ref 45). (b) Life table analysis of survival of patients with hepatocellular carcinoma - comparison between patients in Uganda $a^{46}$ and $\mathcal{F}_{\text {apan. }}{ }^{45}$ (Reproduced by courtesy of $\mathrm{Br} J$ Cancer.)

because of the progression of extrahepatic metastases. ${ }^{42}$

\section{CARCINOID TUMOURS}

This period has seen major improvement in the symptomatic control of carcinoid tumours. Although cytotoxic chemotherapy with streptozotocin and 5-fluorouracil is more effective than in hepatocellular carcinoma, it has not been shown to improve survival. ${ }^{43}$ As noted above, however, arterial embolisation often gives dramatic symptomatic improval. ${ }^{31}$ Synthetic somatostatin analogues have also led to dramatic improvement in symptoms with less immediate complications than embolisation. ${ }^{44}$

\section{PROGNOSIS}

Survival in patients with malignant liver disease is largely dependent on the size of the tumour and the amount of hepatic reserve. The simplest staging classification for hepatocellular carcinoma is that of $\mathrm{Okuda}^{45}$ (Fig 4a). The prolonged survival of patients with stage I disease should be noted and indeed this is increasing as tumours are being detected earlier by ultrasound or alphafetoprotein screening. It should also be noted that the survival of Japanese patients with stage III disease is similar to that reported from Africa $^{46}$ (Fig 4b). This suggests that, rather than having a particularly malignant form of the disease as is sometimes suggested, African patients with hepatocellular carcinoma probably present, or are detected, later than in other countries.

\section{Current areas of interest}

The central theme of much of the cancer research at the Institute has been in the still controversial area of the relationship between hepatocellular 
carcinoma and cirrhosis. ${ }^{47}$ Our prospective follow up study of patients with cirrhosis now involves over 1400 patients followed for up to 12 years. To date 608 have died, 76 with hepatocellular carcinoma. This unique database may answer some fundamental questions. For example: suppose the signal for progression to hepatocellular carcinoma occurred simultaneously with that for the development of cirrhosis? This might suggest that even if antiviral therapy for hepatitis B virus infection prevented progression to cirrhosis it might still be ineffective in avoiding hepatocellular carcinoma development.

\section{ROLE OF THE HEPATITIS C VIRUS}

After identification and cloning of the hepatitis C virus which is responsible for most parenterally transmitted non-A, non-B hepatitis an assay for anti-hepatitis $C$ virus antibodies was developed. ${ }^{48} \mathrm{Up}$ to $80 \%$ of patients with hepatocellular carcinoma were reported as seropositive in studies from Italy and Spain together with other types of cirrhosis previously categorised as alcoholic, hepatitis B virus related and autoimmune. ${ }^{49}$ Ian McFarlane must take much of the credit for the early recognition that many of the so called positive results among patients with autoimmune chronic active hepatitis may well be 'false positive', associated with hypergammaglobulinaemia. ${ }^{50}$

We have recently shown similar results among patients with hepatitis $C$ virus and had the opportunity to test a new diagnostic system based on synthetic peptides derived from both the structural and non-structural part of the hepatitis $C$ virus genome, and this also suggests that only between one and two thirds of the original positive tests can be confirmed. Although these more specific tests have indeed decreased the number of hepatocellular carcinoma patients testing positive for hepatitis $\mathrm{C}$ virus on the continent of Europe, a substantial proportion remain hepatitis $C$ virus positive by all available tests. In the United Kingdom it seems likely that its most important implication will be as a cause of a substantial number of cases of 'alcoholic cirrhosis' rather than as a major aetiological factor in hepatocellular carcinoma.

\section{MORE SENSITIVE TUMOUR MARKERS}

One of the major potential roles of serum AFP measurement, distinct from its use for diagnosis in symptomatic patients, lies in screening asymptomatic cirrhotic patients with a view to early diagnosis which, as noted above, does seem worthwhile when skilled surgery and/or transplantation are available. A problem soon became apparent, however, small, asymptomatic, tumours tended to have only mildly raised concentrations [in the range $20-500 \mathrm{ng} / \mathrm{ml}$ ], at which there is some overlap with uncomplicated chronic liver disease. Several studies showed that alphafetoprotein derived from patients with chronic liver disease (or other non-malignant conditions such as fulminant hepatic failure or pregnancy) was qualitatively different from that derived from hepatocellular carcinoma in terms

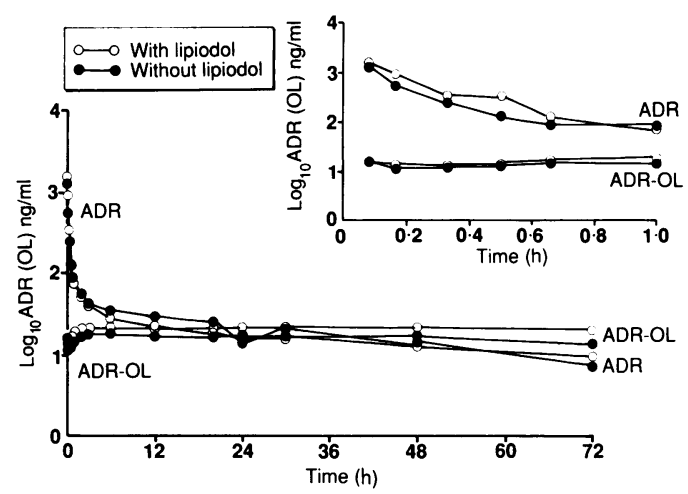

Figure 5: Pharmacokinetics of adriamycin $(A D R)$ and its major metabolite adriamycinol ( $A D R-O L)$ after intraarterial adriamycin with and without lipiodol. The coadministration of lipiodol appeared to have no significant effect (from ref 54). (Reproduced by courtesy of Journal of Hepatology.)

of binding to various lectins, particularly lentil lectin. This implied increased fucosylation of the protein and Winston Hutchinson and Ming Qing Du have recently shown that such abnormalities could be detected even amongst hepatocellular carcinoma patients who had concentrations of alphafetoprotein below $400 \mathrm{ng} / \mathrm{ml}$ - that is, concentrations which are, quantitatively not considered diagnostic. ${ }^{51}$ They also showed that the underlying mechanism of these changes is probably related to disturbances of enzymatic control particularly involving fucosyltransferases which are very active in both the serum and tissue of hepatocellular carcinoma patients. ${ }^{52}$

\section{TARGETING OF CYTOTOXIC DRUGS}

In attempts to increase selectivity, cytotoxic agents have been linked to polyclonal and monoclonal antibodies and lipiodol, an agent which, as previously noted, localises in tumour tissues after arterial administration. Several groups from Japan and the Far East have suggested that this is an ideal method for targeting cytotoxic drugs, because it leads to increased concentration of drug in the tumour and therefore to increased clinical efficacy and might be expected to decrease systemic toxicity. In an extensive series of studies, Cem Kalayci showed that the coadministration of lipiodol had very little affect on the pharmacokinetics, toxicity or clinical efficacy of adriamycin (Fig 5)..$^{534}$ It was concluded that previous favourable results were the result of other methods of treatment administered at the same time as the lipiodol chemotherapy, particularly arterial embolisation.

\section{GROWTH FACTORS}

The autocrine mechanism of cellular transformation is probably one of the most frequent initiators of tumourigenesis. ${ }^{55}$ Cells that possess specific receptors for the polypeptides they secrete, produce either or both ligand and receptor in an uncontrolled fashion. Increased insulin like growth factor II mRNA transcripts have been reported in the hepatocellular carcinoma developing in woodchucks infected with hepadna virus ${ }^{56}$ and recently, using in situ hybridisation Carolyn d'Arville and Kayhan Nouri-Aria have shown that the expression of insulin like growth factor II mRNA is upreg- 
ulated in hepatocellular carcinoma tissue where there is cirrhosis and when the patients are carriers of the hepatitis B virus. ${ }^{57}$

\section{The future}

Assuming that current vaccines remain effective, the eradication of hepatitis $B$ (and later, perhaps hepatitis C) could probably eliminate most hepatocellular carcinoma in the East within 50 years. In the West, control of excessive alcohol consumption would probably be almost as effective. To this extent medical science has offered the solutions - their implementation is dependent on financial considerations and political will.

The search for the mechanism by which hepatitis B virus is oncogenic (if indeed it is!) is the next great prize - there may well turn out to be several different mechanisms. At present it seems most likely that a cellular oncogene is activated by integration of viral DNA and its promoter sequence upstream from the oncogene. Alternatively, viral DNA integration is an essential step but it is subsequently eliminated from the site of action leaving a permanent deletion - the so called 'hit and run' hypothesis.

The concept of early diagnosis will perhaps need to be redefined with respect to hepatocellular carcinoma. The results of 'too late' diagnosis are only too well recognised; those of 'too early' diagnosis are only just being recognised. There is probably just a brief window of opportunity when the tumour is sufficiently large that we can be sure that it poses a significant threat to its host and yet is small enough to be successfully resected. An important recent study suggests that adenomatous hyperplasia may be the true precancerous lesion but detection of such foci will provide major therapeutic dilemmas. ${ }^{58}$ Hilar cholangiocarcinoma remains a major problem - often impossible to diagnose or treat effectively.

The role of screening high risk populations with a view to early diagnosis remains contentious and its potential value in different countries is being actively investigated. In the United Kingdom it seems unlikely to have a major impact, as the high risk groups (namely carriers of the hepatitis $B$ virus and patients with cirrhosis) are seldom identified before the development of tumour. ${ }^{59}$

\section{Conclusions}

Many of the advances in the field of hepatic oncology have arisen from chance observations in unrelated fields and progress seems to have been haphazard. More 'goal directed' research, exemplified by the cloning of the hepatitis $C$ virus by commercial and pharmaceutical companies can be seen as a way of overcoming the prodigious expense of such research. The down side, however, including reluctance to publish in conventional scientific journals, and the patenting of genetic sequences has become all too apparent. There is no such thing as a free diagnostic test or vaccine; the health service will ultimately have to cover research costs.

If the potential for research in this important and intellectually intriguing area is great, many of those committed to research in a hospital environment have not been reassured by recent Government attitudes which appear to undervalue the role of research as an integral part of the health service. So much of what has been useful in the Institute's contributions has resulted from wide and free referral of patients even when, as is the case with hepatocellular carcinoma, no definitive therapy is available. The likely deleterious impact of an internal market for patients on such free referral should not be underestimated.

Finally, it is sobering to recall that behind all the Institute's academic endeavour and publications, each point on the accompanying figures usually represents one person suffering from these devastating forms of cancer. These were all cared for as patients on our wards. The management of those whom we have no way to cure is perhaps the most demanding of all clinical disciplines, and the best reason for continued research.

1 Beasley RP. Hepatitis B virus as the etiologic agent in hepatocellular carcinoma-epidemiologic considerations. Hepatology 1982; 2: 215-21.

2 Beasley RP, Hwang LY, Lin CC, Chein CS. Hepatocellular carcinoma and hepatitis B virus. A prospective study of 22707 men in Taiwan. Lancet 1981; ii: 1129-32.

3 Shafritz D, Shouval D, Shermann HI, Hadzyiyannis SJ, Kew MJ. Integration of hepatitis B virus DNA into the genome of the liver cells and in chronic liver disease and hepatocellular carcinoma. N Engl F Med 1981; 305: 1067-73.

4 Summers J, Smolec JM, Snyder RL. A virus similar to human hepatitis B virus associated with hepatitis and hepatoma in woodchuck. Proc Natl Acad Sci USA 1978; 75: 4533-7.

5 Brechot C, Nalpas B, Courouce AM, et al. Evidence that hepatitis virus has a role in liver cell carcinoma in alcoholic liver disease. N Englf Med 1982; 306: 1384-7.

6 Walter E, Blum HE, Meier P, et al. Hepatocellular carcinoma in alcoholic liver disease: no evidence for a pathogenetic role of hepatitis B virus infection. Hepatology 1988; 8: 745-9.

7 White YS, Johnson PJ, Davison F, Williams R. Frequency of hepatic HBV-DNA in patients with cirrhosis and hepatocellular carcinoma: relation to serum HBV markers. Brf Cancer 1990; 61: 909-12.

8 Parker RGF. The incidence of primary hepatic carcinoma in cirrhosis. Proc R Soc Med 1956; 50: 145-7.

9 Zaman SN, Melia WM, Johnson RD, Johnson PJ, Williams R. Risk factors for the development of hepatocellular carcinoma in cirrhosis. A prospective study of 613 patients. carcinoma in cirrhosis. A

10 Andervont $\mathrm{HB}$. Studies on the occurrence of spontaneous hepatomas in mice of strain $\mathrm{C}_{3} \mathrm{~B}$ and $\mathrm{CAB}$. $\mathrm{F}$ Natl Cancer Inst 1952; 11: 581-91.

11 Leonard B. The use of rodents for studies of toxicity in contraceptive research. Acta Endocrinol 1974; 75: Suppl 185: $34-64$.

12 Baum JK, Holtz F, Bookstein JJ, Klein EW. Possible association between benign hepatomas and oral contraceptive. Lancet 1981; ii: 926-9.

13 Neuberger J, Forman D, Doll R, Williams R. Oral contraceptives and hepatocellular carcinoma. $\mathrm{Br}$ Med $\mathcal{F} 1986 ; 292$ $1355-57$.

14 Iqbal MJ, Wilkinson ML, Johnson PJ, Williams R. Sex steroid receptor proteins in foetal, adult and malignant human liver tissue. Br $\mathcal{C}$ Cancer 1983; 48: 791-6.

15 Wilkinson ML, Iqbal MJ, Williams R. Characterisation of high affinity binding sites of androgens in primary hepatocellular carcinoma. Clin Chim Acta 1985; 152: 105-13.

16 Nagasue $\mathrm{N}$, Ito A, Yukaya $\mathrm{H}$, et al. Androgen receptors in hepatocellular carcinoma and surrounding parenchyma. Gastroenterology 1985; 89: 643-7.

17 Wilkinson ML, Iqbal MJ, Williams R. A new sex-steroid binding protein in foetal liver. ICRS Med Sci 1983; 11: 1123-4.

18 Tatarinov YS. Detection of embryo specific-globulin in blood serum of a patient with primary liver cancer. Vopr Med Khim serum of a patie

19 Johnson PJ, Williams R, Thomas H, Sherlock S, MurrayLyon IM. Induction of remission in hepatocellular carcinoma with doxorubicin. Lancet 1978; i: 1006-9.

20 Johnson PJ, Williams R. Serum alpha-fetoprotein estimations and doubling time in hepatocellular carcinoma: Influence of therapy and possible value in early detection. $\mathcal{F}$ Natl Cancer Inst 1980; 64: 1329-32.

21 Craig JR, Peters RL, Omata M. Fibrolamellar carcinoma of the liver: a tumour of adolescents and young adults with distinctive clinico-pathologic features. Cancer 1980; 46: 372-9. 
22 Paradinas FJ, Melia WM, Wilkinson ML, et al. High serum vitamin B12 binding capacity as a marker of the fibrolamellar variant of hepatocellular carcinoma. $\mathrm{Br} M e d \mathcal{F} 1982 ; 285$ 840-2.

23 Okuda K. Advances in hepatobiliary ultrasonography. Hepatology 1981; 1: 662-71.

24 Ebara $M$, Ohto $M$, Shinagawa $T$, et al. Natural history of minute hepatocellular carcinoma smaller than three centiminute hepatocellular carcinoma smaller than three centimetres $289-98$.

25 Yumoto $\mathrm{Y}$, Jinno K, Tokuyama K. Intrahepatic administration of lipiodol for detection of minute hepatocellular carcinoma. Radiology 1985; 154: 19-24.

26 Raby N, Karani J, Michell M, Gimson A, Nunnerly H, Williams R. Lipiodol enhanced CT scanning in assessment of hepatocellular carcinoma. Clin Radiol 1989; 40: 480-5.

27 Karani J. Tumours: benign: primary malignant. Imaging of the liver, pancreas and spleen. Wilkins $\mathrm{R}$, Nunnerly $\mathrm{HB}$, eds. Oxford: Blackwell 1990: 172-86.

28 Pain J, Karani J, Howard E. Clinical and radiological assessment of liver tumours: Is biopsy necessary? Clin Radiol 1991 (in press).

29 Raeth U, Johnson PJ, Williams R. Ultrasound determination of liver size and assessment of patients with malignant liver disease. Liver 1984; 4: 287-93.

30 Murray-Lyon IM, Dawson JL, Parsons VA, et al. The treatment of secondary hepatic tumours by ligation of hepatic artery and infusion of cytotoxic drugs. Lancet 1970 ii: $172-4$.

31 Melia WM, Nunnerly HB, Johnson PJ, Williams R. Use of arterial devascularization and cytotoxic drugs in 30 patients with carcinoid syndrome. Br f Cancer 1982; 46: 331-8.

32 Fletcher MS, Brinkley D, Dawson JL, et al. Treatment of high bile duct carcinoma by internal radiotherapy with iridium-192 wire. Lancet 1981 ; ii: $172-4$.

33 Hatfield ARW. Palliation of malignant obstructive jaundice surgery or stent? Gut 1990; 31: 1339-40.

34 Bismuth H, Houssin D, Ornowski J, Meriggi F. Liver resection in cirrhotic patients-a Western experience. Wld f Surg 1986; 10: 311-7.

35 Polydorou AA, Dowsett JF, Cairns SR, et al. Palliation of proximal malignant biliary obstruction by endoscopic endoprosthesis insertion. [Abstract[ Gastroenterology 1989; 96: A203.

36 Smith AC, Dowsett JF, Hatfield ARW, et al A prospective randomised trial of by-pass surgery versus endoscopic randomised trial of by-pass surgery versus endoscopic stenting in patients with maligen

37 Hughes KS, Simon R, Songhorabodi S, et al. Resection of the liver for colonic carcinoma metastases: a multi institutional study of indications for resection. Surgery 1988; 103: 278-84.

38 O'Grady J, Poulsen RT, Rolles K, et al. Liver transplantation for malignant liver disease. Ann Surg 1988; 207: 373-7.

39 Melia WM, Johnson PJ, Williams R. Controlled trial of Doxorubicin and Tamoxifen versus Doxorubicin alone in hepatocellular carcinoma. Cancer Treat Rev 1987; 71: 1213-6.

40 Farinati $F$, Salvagnini $M$, de Maria $N$, et al. Unresectable hepatocellular carcinoma: a prospective controlled trial with hepatocellular carcinoma: a prospective con

41 Forbes A, Wilkinson ML, Iqbal MJ, Johnson PJ, Williams R. Response to cyproterone acetate treatment in primary hepatocellular carcinoma is related to fall in free 5a-dihydrotestosterone. Eur $\mathcal{F}$ Cancer Clin Oncol 1987; 23: 1659-64.

42 Kemeny N, Daly J, Reichman B, et al. Intrahepatic or systemic infusion of fluorodeoxyuridine in patients with liver metastases from colorectal carcinoma. Ann Intern Med 1987; 107: 459-65.

43 Moertel CG, Hanley JA. Combination chemotherapy trials in metastatic carcinoid tumor and malignant carcinoid synmetastatic carcinoid tumor and malignan
drome. Cancer Clin Trials 1979; 2: 327-34.

$44 \mathrm{Kvols}$ LK. Treatment of the malignant carcinoid syndrome. Evaluation of a long acting somatostatin analogue. $N E n g l f$ Med 1986; 315: 613-16.

45 Okuda K, Ohtsuki T, Obata H, et al. Natural history of hepatocellular carcinoma and prognosis in relation to treatment. Cancer 1985; 56: 918-28.

46 Primack A, Vogel CL, Kyalwazi SK, et al. A staging system for hepatocellular carcinoma: prognostic factors in Ugandan patients. Cancer 1975; 35: 1357-64.

47 Johnson PJ, Williams R. Cirrhosis and the aetiology of hepatocellular carcinoma. $\mathcal{F}$ Hepatol 1987; 4: 140-7.

$48 \mathrm{Koo}$ G, Choo Q-L, Alter HJ, et al. An assay for circulating antibodies to a major etiologic virus of human non-A non-B antibodies to a major etiologic virus

49 Bruix J, Calvet X, Costa J, et al. Prevalence of antibodies to hepatitis C virus in Spanish patients with hepatocellula carcinoma and hepatic cirrhosis. Lancet 1989; ii: 1004-6.

50 McFarlane IG, Smith HM, Johnson PJ, Bray G, Vergani D, Williams $R$ : Hepatitis $C$ virus antibodies in chronic active hepatitis: pathogenetic factor or false positive result?: Lancet 1990; i: 754-7.

51 Hutchinson WL, Du M-Q, Johnson PJ, Williams R. Fucosyltransferases: Differential plasma and tissue alterations in hepatocellular carcinoma and chronic liver disease. Hepatology 1991 (in press).

52 Du M-Q, Hutchinson WL, Johnson PJ, Williams R. Differential alphafetoprotein lectin binding in hepatocellular carcinoma: diagnostic utility at low serum levels. Cancer 1991 ; 67: 476-80.

53 Kalayci C, Johnson PJ, Raby N, Metivier EM, Williams R Intraarterial adriamycin and lipiodol for inoperable hepatocellular carcinoma: A comparison with intravenous adriamycin. F Hepatol 1990; 11: 349-53.

54 Johnson PJ, Kalayci C, Dobbs N, et al. Pharmacokinetic and toxicity of intraaterial adriamycin for hepatocellular carcinoma: effect of coadministration of lipiodol. 7 Hepatol 1991 (in press).

55 d'Arville CN, Johnson PJ. Growth factors, endocrine aspects and hormonal treatment in hepatocellular carcinoma - an overview. I Steroid Biochem Molec Biol 1990; 6: 1007-12.

56 Rogler CE, Hino O, Su CY. Molecular aspects of persisten woodchuck hepatitis virus and hepatitis B virus infection and hepatocellular carcinoma. Hepatology 1987; 7: 74s-8s.

57 d'Arville CN, Nouri-Aria KT, Johnson PJ, Williams R. Regulation of insulin-like growth factor II gene expression by hepatitis B virus in hepatocellular carcinoma. Hepatolog 1991; 13: 310-15.

58 Takayama T, Makuuchi M, Hirohashi S, et al. Malignant transformation of adenomatous hyperplasia to hepatotransformation of adenomatous hyperplas

59 Zaman SN, Johnson PJ, Williams R. Silent cirrhosis in patients with hepatocellular carcinoma. Implications for population screening. Cancer 1990; 65: 1607-610. 